\title{
Declaración de Tlaxcala de La Via Campesina (1996)
}

Via Campesina

Nosotros, la Via Campesina, un movimiento en crecimiento de organizaciones de campesinos y agricultores de todas las regiones del Planeta (Asia, Europa, las Américas y África) nos hemos reunido para nuestra Segunda Conferencia en Tlaxcala, México, con el propósito de reafirmar nuestro compromiso con las metas vitales de nuestros pueblos. Los representantes de 69 organizaciones de 37 países se reunieron los días 18 al 21 del mes de abril de 1996. Este encuentro histórico muestra la naturaleza dinámica de nuestra solidaridad y de nuestra determinación para avanzar en la defensa de los que viven de la tierra y en la construcción de mejores alternativas.

Frente a un ambiente cada vez más hostil a los campesinos y pequeños agricultores en todo el mundo, nuestra respuesta es desafiar de forma colectiva sus condiciones. Nos une el rechazo a las condiciones económicas y políticas que destruyen nuestras formas de sustento, nuestras comunidades, nuestras culturales y nuestro ambiente natural. Estamos determinados a crear una económica rural basada en el respeto a nosotros mismos y a la tierra, sobre la base de la soberanía alimentaría, y de un comercio justo. Asegurar el desarrollo rural incluyente, que reconozca la importancia de la contribución de las mujeres en la producción de alimentos, es nuestro compromiso. Exigimos una reforma agraria autentica que devuelva sus territorios a los pueblos indígenas, que le otorgue a los campesinos sin tierra y a los agricultores pequeños propiedad y control de la tierra que trabajan. 
El sistema económico neoliberal prevalente a nivel mundial, ha sido la causa principal del empobrecimiento de los agricultores pequeños $y$, en general, de la gente del campo. Es responsable del incremento en la destrucción de la naturaleza, la tierra, el agua, las plantas, los animales y los recursos naturales, poniendo todos estos recursos bajo la égida de sistemas centralizados de producción, abasto y distribución de productos agrícolas en el marco de un sistema orientado a un mercado global. Este sistema económico trata a la naturaleza y a los seres humanos como simple medio para un fin, con el único propósito de generar ganancias. La concentración de toda esta riqueza en las manos de unos pocos, coloca a los agricultores bajo increíbles presiones en todo el mundo, llevándolos inexorablemente al borde de la extinción. La tierra, la riqueza y el poder en manos de grandes terratenientes y de las corporaciones transnacionales, les niega de manera injustificada a los campesinos y a los pequeños productores la posibilidad de controlar su propio destino. Las políticas de dumping social, las situaciones de pobreza endémica y el incremento de la marginación en el Tercer Mundo, producto de la deuda externa, destruyen las esperanzas de millones de personas. Los problemas sociales serios y la deficiencia de los servicios básicos, a la par de la opresión que sufren las minorías étnicas y los pueblos indígenas, agravan las situaciones de injusticia y frustración.

El racismo prevalente y su incremento en el mundo rural, es inaceptable. No podemos tolerar el desplazamiento continuo, la urbanización forzada y la represión de los campesinos. Denunciamos con fuerza toda forma de violencia en su contra. Particularmente censuramos profundamente la brutal y trágica masacre de 23 campesinos en el Brasil, el día 17 de abril de 1996. Esta terrible acción es sin duda otro golpe cuyo propósito es intimidar a aquellos que buscan justicia. No nos intimidaran. Por la presente declaramos al 17 de abril. "Día Internacional para protestar en contra de la opresión campesina, en cualquier parte del mundo". Se hizo notar en la Conferencia que la Organización de las Naciones Unidas para la Agricultura y la Alimentación (FAO), celebrara una Cumbre a nivel mundial sobre Alimentación, durante el mes de noviembre de 1996, con el ostentoso propó- 
sito de resolver el problema de millones de personas que enfrentan la escasez de alimentos y la desnutrición.

No podrá solucionarse este problema sin la participación activa de los que cultivan la tierra. Los delegados tomaron la decisión de que la Via Campesina debe estar en esta Cumbre, debidamente representada. Denunciamos las actividades neoliberales del Banco Mundial y del FMI, cuyas políticas de reajuste estructural imponen un precio demasiado alto que es inaceptable para los pobres y los campesinos en muchos de nuestros países. Estas políticas reducen la capacidad de los gobiernos de los países en desarrollo, para proporcionar servicios básicos. En lugar de buscar una solución duradera a la crisis de la deuda externa, con estas políticas la situación simplemente se ha empeorado. Muchas de estas deudas son impagables. La Conferencia exige que estas deudas y el programa de ajuste estructural que destruye sean proscritos, a favor de un desarrollo rural nacional autosuficiente. Las instituciones financieras internacionales deben democratizarse para que, de esa forma, respondan a las necesidades reales de la mayoría de las personas.

La Conferencia deplora los acuerdos hechos por las corporaciones multinacionales para apropiarse de los recursos genéticos. La Via Campesina se opone enérgicamente a este proceso y tomara una posición decidida en la "Cumbre Mundial sobre Semillas", a realizarse en Leipzig, Alemania, durante el mes de junio de 1996. La Via Campesina tiene la determinación de influir sobre la Organización Mundial de Comercio, para promover cambios en los acuerdos comerciales existentes. Los acuerdos comerciales internacionales deben tomar en cuenta, plenamente, los intereses de los campesinos y los agricultores pequeños.

Entre nuestras estrategias paralograr nuestros objetivos se encuentran:

- Articular y fortalecer las organizaciones regionales, particularmente en Asia y África.

- Desarrollar respuestas regionales apropiadas ante tratados comerciales bilaterales y regionales como el Mercosur, TLC, APEC, etcétera. 
- Poner en la palestra internacional los objetivos de la Via Campesina, en organismos como: FAO, FMI, BM, OMC, así como en otros foros internacionales de la Organización de las naciones Unidas y de la OIT.

- Construir relaciones de solidaridad entre las organizaciones miembros de la Via Campesina.

- Promover el trabajo organizativo por medio de la creación de redes entre las mujeres de la Via Campesina y de sus organizaciones.

- Construir secretarias operativas a nivel regional.

- Fomentar mecanismos de comunicación interna y externa, que le facilite a la Via Campesina abordar de forma expedita las problemáticas emergentes (esto incluiría un boletín interno bimensual y procedimientos para sacar comunicados de prensa via Internet).

- La Comisión Coordinadora promoverá el trabajo organizativo por medio de la creación de redes, entre los distintos sectores de la producción a nivel regional y entre las regiones.

- Promover iniciativas que contribuyan al desarrollo del comercio justo con la concurrencia directa de los productores y consumidores, comenzado con una campaña internacional anti-dumping.

- Instigar una "red de solidaridad y respuesta" en contra de los actos de violencia ejercida en contra de los campesinos y los pequeños agricultores, ampliando el movimiento por medio de la participación de diversos actores sociales.

- Luchar en contra del proceso de privatización de patentes en materia genética, por medio de la creación de bancos de semillas para los agricultores, proponiendo iniciativas legales que aseguren el patrimonio genético e informando sobre los peligros que entraña la bioprospectiva. 
Consideramos que nuestra Conferencia en Tlaxcala, México, es un enorme e importante paso en dirección a la justicia, la equidad y la libertad para los que viven y trabajan en el campo, en cualquier parte del mundo.

La Trinidad, Tlaxcala, 21 de abril de 1996 